Original Research Paper

\title{
The Intersectionality of Leadership (Styles) and Broadening Participation in STEM at HBCUs
}

\author{
Nisha Naomi Clavier, Kimarie Engerman, Camille A. McKayle and Mohomodou Boncana \\ Center for the Advancement of STEM Leadership, University of the Virgin Islands, Virgin Islands
}

\author{
Article history \\ Received: $30-11-2020$ \\ Revised: 01-02-2021 \\ Accepted: 22-02-2021 \\ Corresponding Author: \\ Nisha Naomi Clavier \\ Center for the Advancement of \\ STEM Leadership, University \\ of the Virgin Islands, Virgin \\ Islands \\ Email:nclavie@uvi.edu
}

\begin{abstract}
The term leadership has been dissected, analyzed and even quantified over numerous years. Leadership in STEM has also been extensively researched. Its results are used to educate and guide decision and to enact policies. However, despite the abundance of literature available on leadership and STEM in general, research falls short when it comes to examining leadership characteristics and its relationship to broadening participation at institutions of higher education, specifically Historically Black Colleges and Universities (HBCUs). Of special interest is the growing awareness that HBCUs have been producing high percentages of STEM graduates for many years. CASL, the Center for Advancement of STEM Leadership, aims to discover the leadership styles, characteristics and practices that may be influencing the large production of STEM graduates from HBCUs and contribute to the general body of knowledge on leadership. Semi-structured interviews served as the source of data from HBCU leaders' perspectives. The results of this analysis will assist with increasing the general population's awareness and knowledge of the impact of HBCUs' leadership on broadening participation in STEM. The results also inform leaders of educational institutions across the nation regarding the benefits of exploring, or implementing, uncovered leadership styles and practices to broaden participation in STEM.
\end{abstract}

Keywords: HBCUs, STEM, Leadership Styles, Academic Frames, Broadening Participation

\section{Introduction}

An organization's leadership style plays an important role in its success (Bukit et al., 2019). The behaviors of leaders, which drive their individual success (Heimann et al., 2020), can also make a positive impact on an organization's success. Leadership is a necessary component that fosters innovation, creates enthusiasm, creates focus and motivates others (Shah, 2018). The right leadership style will encourage employees to work optimally while achieving organization objectives (Bukit et al., 2019). Policies, staff and customers are some of the ever-changing factors within establishments and their survival often requires the adoption of an effective leadership approach which is not heavily reliant on being "organized and making organizational arrangements" (Ikinci, 2014).

For leadership to be effective, it requires effective communication, effective behavior, good ethics and an effective style from its members (Shah, 2018). Effective leaders believe that people want to excel, so they create an environment in which success is not only possible, but also contagious (Cismas et al., 2016). Effective organizations are able to find a balance between meeting its stakeholders' demands and employees' needs (Hurduzeu, 2015) and they also hire leaders who can find the right balance between exploring future opportunities and challenges while efficiently implementing current activities (Diana-Nicoleta et al., 2019). With an effective leadership team, an organization can witness growth in its performance and a positive change in its overall structure (Thapa, 2016).

\section{Literature on Leadership Styles}

The vast amount of research on leadership has yielded various types of leadership styles: Responsible, transformational, ethical, authentic and servant, among others. Pless and Maak (2011) defined responsible leadership as a value-based and ethical approach that 
creates a relationship between stakeholders and leaders. The connection provides an avenue for the members' shared sense of meaning and purpose to raise one another to higher levels of commitment through which they can achieve sustainable values and bring about social change. Responsible leadership differs from other traditional forms because of its focus on society, value creation and change (Han et al., 2019). Responsible leaders should possess the emotional intelligence required to understand the "need for and value of people from various backgrounds and engage them for a common end" (Mehta et al., 2020).

Ethical leadership, a popular subject in recent leadership research (Kaptein, 2019), influences followers by demonstrating ethical conduct, often through transactional mechanisms (Pless and Maak, 2011). Ethical leaders act virtuously, ensure ethical and prosocial conduct in the workplace, use moral reasoning to make decisions (Pless and Maak, 2011) and can operate as a moral entrepreneur creating new ethical norms (Kaptein, 2019). Ethical leadership also seeks to predict outcomes, such as leader effectiveness and employee job satisfaction and aspires to mobilize followers to engage in responsible leadership practices (Pless and Maak, 2011).

Servant leadership centers, primarily, on the followers. It is other-directed, rather than on the leader's self-orientation and bears similarity to responsible leadership in its idea that leadership is mainly about the leader's constituents (Pless and Maak, 2011). Servant leadership can also be viewed as a "holistic approach that engages followers in multiple dimensions... such that they are empowered to grow into what they are capable of becoming" (Eva et al., 2019). The task of a servant leader is to serve the needs and legitimate interests of others. Leaders and followers should raise each other's motivation and morality.

Pless and Maak (2011) referenced Luthans and Avolio's definition of authentic leadership as a "process that draws on both positive psychological capacities and a highly developed organizational context" (p. 7). Azanza et al. (2013) state that authentic leaders show hope, optimism and other positive orientations towards the future. An authentic leader influences, energizes and develops followers and helps them find meaning at work. They also aid in contributing to sustained performance and growth (Pless and Maak, 2011).

According to (Pless and Maak, 2011), transformational leadership builds commitment and empowerment among followers to accomplish organizational goals and enhance follower performance. It shares similar notions with responsible leadership (vision, inspiration, etc.) and influences followers for the sole purpose of enhancing performance and accomplishing organizational objectives (Pless and Maak, 2011).

\section{Research on Leadership Styles Across Disciplines}

Uncovering the key to effective leadership has been a focal point for many years and across a broad range of fields. Extensive research on the topic has yielded new insights into various professions. Saxena et al. (2017) examined Goleman's leadership styles at different hierarchical levels in medical education and concluded that utilizing four or more styles creates highly effective leaders. Their study also indicated that leadership is a process of intentional influence and its development should be aimed at effective leadership behaviors.

Saleem et al. (2020) evaluated the effects of private secondary school principals' leadership styles on teachers' job performance and suggested that of the four styles (directive, participative, supportive and achievement-oriented), leaders who utilized directive leadership generally had the largest significant positive effect on teacher performance. Regardless of the field that leadership research is aimed at, there is no disagreement with the fact that it is integral to success of an organization.

Another study, conducted in Pakistan, examined the interplay of leadership styles, innovative work behavior, organizational culture and organizational citizenship behavior (Khan et al., 2020). The study aimed to uncover the effect on leadership styles on organizational culture and organization of department heads at institutions of higher education. The results of the study indicate that transactional and transformative leadership styles have a significant effect on innovative work behavior. In contrast, a lassiez-faire leadership style had no effect on innovative work behavior

\section{Examining Leadership using Academically Framed Lenses}

For years, leadership has been analyzed through industrial lenses (Dugan and Komives, 2010). There is an abundance of research on the effects of the different types of leadership styles across many research fields, but limited research on the four academic frames through which (Bolman and Deal, 1991; Bolman and Gallos, 2011) suggested that academic leadership be viewed: Structural, political, symbolic and human resource. Structural leaders seek to analyze the key features and needs of an organization and its environment in order to build capacity. They also determine the right roles, rules and arrangements in order to transform a variety of inputs into outputs. Outputs are referred to as educated graduates, journal articles, books and others. Bolman and Gallos (2011) continue to state that there are two roles that college and university leaders play when utilizing the structural frame: Analysts and institutional architects/system designers. Analysts 
study the institution's production processes, while architects "develop rules, roles and policies, reporting relationships and procedures that align efforts with campus goals" (p. 51).

The second frame, political, focuses on the needs and concerns of internal and external stakeholders. This viewpoint sees academic institutions as "vibrant ecosystems that house a variety of different species or groups, each with its own specific characteristics, capabilities, interest, needs and lifestyles" (p. 71). Political leaders negotiate, advocate, strategize and build coalitions. It is important that these leaders are credible and persuasive when promoting the interests of their unit or organization. They must also have the ability to conduct negotiations with leaders at external organizations or with groups that possess the resources or support they may need.

Symbolic leaders are the third frame and these leaders focus on issues of meaning and belief. They tell the story of the preferred future, inspire the team and keep the mission and vision of the organization at the forefront. In addition to this, creating a common vision and leading by example are paramount. Institutions of higher education are viewed as sacred places whose:

Legitimacy rests ultimately on faith in the transformational power of knowledge and as a theater whose success derives from staging powerful dramas that connect and communicate to important audiences (p. 108).

The fourth frame, human resource leaders, support, challenge, encourage and coach those on their team. They view employees as resources to be developed so they maximize their potential in service to the mission. They focus on creating productive relationships and view relationships as vital to organizational success.

\section{The Impetus to Broaden Participation in STEM}

In the United States (U.S.), there is an overall perception of underperformance in area of Science, Technology, Engineering and Math (STEM) education and the topic of STEM is often raised in different policy debates (Gonzalez and Kuenzi, 2012). Currently, there is an increased demand for STEM education and programs and (Lancaster and $\mathrm{Xu}, 2017$ ) speculated that the increased demand was created by shifts in market forces which resulted in reshaping the global economy. The 1950's launch of the Soviet Union's Sputnik satellite was also cited as a key turning point for STEM education policies (Gonzalez and Kuenzi, 2012).

According to the (U.S. Department of Education, 2020a), fluency in STEM fields is "essential" if the nation hopes to generate leaders who can understand and solve complex challenges and meet the demands of the workforce. However, the U.S. has been unable to produce STEM graduates at a rate proportionate to the needs in the workforce and, because of this shortfall, jobs in STEM fields will consequently go overseas (Lancaster and $\mathrm{Xu}, 2017$ ). Attaining diversity in STEM is of an utmost importance and, according to (Miriti, 2019), the biggest challenge to this achievement is a lack of broad participation.

To combat this growing concern, organizations such as the National Science Foundation (NSF) and the DOE appropriated funding specific to initiatives that create and provide access to STEM programs for students and the community. States such as North Carolina and Texas, are promoting Inclusive STEM High Schools (ISHS) (Means et al., 2018) and projects that create and/or evaluate the effectiveness of ISHS are now available.

A research collaboration between SRI International, George Washington University and George Mason University, funded by the National Science Foundation, created the Opportunity for Structures for Preparation and Inspiration (OSPrI) and iSTEM for broadening participation in STEM. The OSPrI project examined opportunities provided to students by ISHSs, while the iSTEM project studied the impacts of ISHSs in the United States via a longitudinal study (Insights Into Inclusive STEM High Schools, 2020).

The results of the first OSPrI case study of an ISHS in Texas showed that there was a high percentage (84\%) of the Class of 2010's college/university bound students who were accepted into four-year universities, with $62 \%$ of that group being first-generation college goers (Lynch et al., 2013). While the report did not specify which fields the students pursued, these statistics highlighted an achievement from a STEM focused educational facility. In support of the ISHS pipeline to post-secondary STEM enrollment, the study conducted by (Means et al., 2018) indicated that students who attended inclusive STEM high schools were significantly more likely to be enrolled a STEM bachelor's degree two years after graduating.

\section{The Evolution of HBCUs and Broadening Participation}

STEM and effective leadership are two equally important aspects of the economy and education, specifically at Historically Black Colleges and Universities (HBCUs). The effectiveness of leadership at universities, specifically HBCUs, is necessary for the continued success of the institution (Hines, 2014). However, to truly understand the uniqueness of leadership at HBCUs, which impacted broadening participation in STEM, one should be knowledgeable of HBCUs' histories, which dates back to well over a century. The first HBCU, Cheyney University, was founded in 1837 with the primary mission of educating Black Americans and teaching them skills to increase their employability (BlackPast, 2020). 
Cheyney's inception, which was no small feat, paved the way for many other HBCUs to follow suit during the 1800s despite facing historical challenges: Accreditation issues, low funding and Jim Crow (TMCF, 2020). Regardless of the difficulties HBCUs faced, their leadership continues to serve students of low economic backgrounds (Harper, 2018). This blend of support collectively and consistently produced increasingly large numbers of college graduates throughout the years, with a growing number of graduates receiving degrees in a STEM major.

\section{HBCU Leadership and STEM}

Historically, leadership at HBCUs was relatively stable with low turnover rates as presidents remained in their role for many years, often decades, until ready for retirement (Watson, 2013). Research indicated that while HBCU presidents still have (on average) longer tenures than their White counterparts, their years of service are much shorter than years ago. According to (Watson, 2013), some of the reasons for shortened tenures include termination due to allegations of fiscal mismanagement and poor retention rates, as well as voluntary resignation as a result of facing the mounting challenges of leading an HBCU.

The 'leadership-success in STEM' phenomena becomes even more intriguing when one considers that HBCUs face added challenges with leadership. In addition to future of HBCUs being at risk because of frequent leadership changes (Watson, 2013 Hines, 2014) listed ineffective leadership as a critical issue facing many HBCUs. According to (Hines, 2014), repeated mismanagement of fiscal, human and academic resources is placing HBCUs at risk of destruction. In recent times, universities such as Stillman College, the University of the District of Columbia and Morgan State University had presidents who were abruptly asked to step down (Watson, 2013). Yet, amidst the growing trend of administrative shakeups at HBCUs, the "increasing number of African Americans studying and working in Science, Technology, Engineering and Math (STEM) fields is revolutionary" (United Negro College Fund, 2020).

\section{STEM Graduation Rates and HBCUs}

Today, there are approximately 101 HBCUs located within 19 states and territories (National Center for Education Statistics, 2020) with more than 228,000 students enrolled (U.S. Department of Education, 2020b). The fact they have been producing high percentages of African American STEM graduates (Flowers et al., 2012), has shone a spotlight on HBCUs. The (U.S. Department of Education, 2020a) reports that more than 80 percent of Black Americans with degrees in medicine and dentistry received training at one of two traditional HBCUs, Howard University and Meharry Medical College. These two institutions award $19.7 \%$ of the degrees in medicine and dentistry to black students (U.S. Department of Education, 2020b) In addition, the DOE stated that HBCUs are the leading institutions in awarding life sciences, physical sciences, mathematics and engineering degrees to black students.

According to the (United Negro College Fund, 2020), $25 \%$ of African American graduates with STEM degrees hail from HBCUs. Owens et al. (2012) conducted a study on 2,906 institutions, which included 88 HBCUs. Their results revealed that $39 \%$ of students who earned degrees in STEM during the 2001-2009 study period were conferred from HBCUs. According to (Owens et al., 2012), there was a difference in the type of STEM degrees that private versus public HBCU graduates earned. Based on their research, public HBCUs produced more computer science, engineering and engineering technology graduates while private HBCUs produced more biomedical, mathematics and statistics and physical sciences graduates. Statistics such as these have prompted this study to explore the reason behind the high production of STEM graduates from HBCUs and uncover whether there is an intersection between leadership styles and broadening participation in STEM. The study asks the following questions: (a) To what extent do leadership styles at HBCUs influence the significant difference in the percentages of STEM graduates?; (b) can an exploration of leadership styles and an analysis of institution outcomes provide insight into this phenomenon?; and (c) what leadership characteristics do they employ that are unique and common across the institutions?

\section{Methodology}

\section{Design}

This was a narrative inquiry study that explored the views of eight deans in relation to their perspectives on leadership styles and broadening participation in STEM at HBCUs. Semi-structured interviews were used to collect the data. Bolman and Gallos' (2011) academic frames (human resource, political, structural and symbolic) were used as a framework to analyze the data.

\section{Participants}

Eight deans from seven different HBCUs participated in semi-structured interviews. Of the eight participants, three were women. The majority of the participating institutions were located in the southeast region of the United States and the remaining institution was located in the northeast region. Six participants were African American and the other two participants were Asian or Latino. 


\begin{tabular}{llll}
\multicolumn{2}{l}{ Table 1: Characteristics of Participating HBCU Institutions } \\
\hline Region & Enrollment size & Award level & Status \\
\hline NE1 & Large & Doctoral & Public \\
SE1 & Small & Masters & Public \\
SE2 & Medium & Bachelors & Private \\
SE3 & Large & Doctoral & Public \\
SE4 & Large & Doctoral & Public \\
SE5 & Large & Doctoral & Public \\
SE6 & Medium & Bachelors & Private \\
SE7 & Small & Masters & Public \\
SE8 & Medium & Doctoral & Private \\
\hline
\end{tabular}

Participating institution sizes and statuses varied: (a) Two small (1 private, 1 public); (b) three medium ( 2 private, 1 public); and (c) three large (all public). For the purpose of this study, the size of an institution was classified based on the numbers of students who enrolled during the study period: Small (700-2500), medium (2501-5000) and large >5000. Table 1 provides a description of the demographics for participating HBCUs.

\section{Data Collection}

The semi-structured interviews lasted approximately one hour and a half and were held in-person at the participants' institution. An example of a statement posed to each participant was, "Please describe your pathway to your current position". Another question asked was, "how would you describe your campus climate regarding STEM and how might that contribute, if at all, to student success in STEM?" The sessions were recorded and transcribed.

Eight transcripts were reviewed. Codes were assigned to statements that aligned with four frames. In some instances, data reflected more than one frame. The extracted codes were discussed as a research team to resolve any discrepancies in coding.

\section{Results}

An analysis of the transcripts revealed participants' perspectives regarding leadership styles and characteristics of leaders at HBCUs and their views on practices that can strengthen a university community or department. Five main themes emerged from the analysis of perspectives: (a) Practices of effective leaders; (b) practices that strengthen student STEM communities; (c) initiatives that strengthen STEM faculty and programs; (d) characteristics of STEM leaders and (e) challenges that impact leadership and broadening participation. Each theme was coded based on one of the four frames (human resource, political, structural, or symbolic) or a blended frame, if the theme aligned with more than one frame.

\section{Practices of Effective Leaders}

\section{Human Resource Themes}

Deans' perspectives regarding creating effective leaders had the most alignment with the human resource frame. The deans felt strongly about the need to invest in themselves and their faculty. The emerging themes highlight behaviors that participants felt were necessary for leaders at HBCUs to do when developing other skilled and efficient leaders.

\section{Participate in and Provide Professional and Leadership Development Opportunities}

Attending leadership and development trainings and workshops was the most recurring theme revealed by the deans. It was generally felt by the participants that their personal leadership skills were enhanced and doors opened when professional development opportunities were taken advantage of during their earlier years. The need for leadership trainings and opportunities for their faculty and students continues to be a priority now that they are in a top administrative role.

One dean, from a large HBCU, felt that the most important training for budding administrative leaders would be focused on management skills, because faculty are a "special population". He continued to state when evaluating leaders, identifying whether they had an academic background was key because $\mathrm{PhD}$ holders "need to be treated differently from ... employees in industries". An additional benefit would be if the trainings also incorporate past experiences of the faculty that have been acknowledged as best practices. Doing this can save time for individuals who are being promoted, for example, from faculty to department chair.

Another dean felt that participating in leadership training is useful and aids in succession planning. He associated the trainings he attended with his succession planning in becoming the dean. At the time of the interview, two of his department chairs were enrolled in a leadership program. When asked what components of a leadership program were particularly important, he responded with learning how to be a servant leader. According to him, servant leadership works best at most levels within a university, with the presidential level being one of the exceptions. In his perspective, many times individuals become "bosses" and do not think much on what the word boss means in an academic environment. It is important for leaders to understand how to make it possible for others to do their work. Leaders should view themselves as an inverted pyramid with the leader being the tip, or at the bottom of the pyramid.

A female dean reflected that her administration had been very supportive of her getting the professional development that she needed. As a result, when she 
became a department chair, she was able to participate in year-long leadership trainings and attend workshops about being a department chair. She expressed that attending those leadership development trainings were very meaningful into codifying whether she wanted to be a leader. For her, attending the trainings and workshops were "very eye-opening" and it showed her where she needed to develop and grow. She summed up her feelings about trainings and stated that being willing to invest in faculty enriches the HBCU environment.

A male dean mentioned that he attended several leadership trainings and workshops prior to becoming a dean at his university. He completed different chair workshops and was also attending a dean's workshop at the time of the interview. According to him, the first few trainings he received as a new chair was most helpful. When asked what he found particularly helpful in the trainings, he mentioned learning about visions, missions, budgets, setting priorities and making the difficult decision to fire someone. He offered that he found most workshops helpful and those that did not were because he knew the information already. Interestingly, this sentiment appeared to contrast with another participant who felt that it was important to incorporate past experiences and knowledge into trainings.

A male dean reflected on attending professional development trainings and workshops prior to becoming the dean and attributed his success to the trainings he received. At his university, the provost selected chairs across the university and encouraged them to attend one full year of training. During the year-long training, chairs met every month and leadership experts from private companies gave presentations and provided opportunities to have hands-on experiences. Some topics covered by the trainings included learning how to work together, communicate, promote the university's vision, understand what makes a company fail and others.

\section{Implement Meaningful Mentoring Strategies}

Mentoring is another theme acknowledged by participants as an important ingredient to developing strong leaders. Most participants received mentoring during some point of their academic career prior to becoming a dean at their institution. One female participant stressed that it was necessary for administration to implement meaningful mentoring strategies for faculty.

A male dean stated that the opportunity to observe and later work closely with, a former dean for approximately six years was critical to his growth. During those mentoring years, he attended trips and meetings and learned how to deal with faculty, organize a team to write proposals and manage resources. Mentoring allowed him to understand the dean's vision for the school and how to work with administration and faculty. As a result of those experiences, he felt that that former dean was one of the best he ever had. Another participant felt that his career path, or trajectory, was greatly influenced by someone else. As a result, he had a greater understanding of the importance of mentoring.

\section{Understand your People}

One participant felt that part of being a leader was having the ability to understand the people that you have and to learn what their strengths and aspirations are. Doing this will provide an avenue to assign tasks that stretch people's abilities, until they feel that they have stretched enough.

\section{Create a Family-Like Environment}

According to one participant, departments within academic institutions often do not work with one another and tend to operate as silos. He disapproved of this practice and expressed that members of the university community should not only view each other as a family, but also work together and trust one another. His goal, as dean, is to remove silos and encourage collaboration, thereby creating a new atmosphere.

\section{Political Themes}

An analysis of the transcripts showed that participants support the practice of collaborating with colleagues and encouraging inter-department collaborations. The themes that emerged highlight behaviors that participants felt were necessary for leaders at HBCUs to do when increasing communication and providing support to the university community.

\section{Encourage Peer Collaborations}

Second to providing professional and leadership development opportunities, collaboration among colleagues was the next most recurring sentiment expressed by participants. Importance was placed on providing opportunities for consultations and collaborations among faculty. One leader felt that while creating an environment for faculty with synergy to collaborate was important, another important layer was to increase inclusivity of other departments and make the groups interdisciplinary. In support of this practice, a male participant stated that he started a major project with the goal of making it available "...to a wide range of people at the university, not just the scientists, not just the STEM people".

\section{The collaborative process allows for divergent and design thinking and a platform to not only think about their research problems but to engage their peers into helping them craft their research ideas, refine their research ideas and make sure that their methods and their strategies are gonna really get to the endpoint that they're looking for.}


According to one participant, collaboration, when combined with strategic planning, is instrumental in informing campus administration of needs and establishing clear visions and objectives for individual own areas. It is imperative that meaningful collaborations among faculty are established so that work can be completed. Other participants felt that collaborations help to facilitate an understanding of the people involved so that they can be employed in meaningful ways in accordance with their skillsets. It also gives faculty the type of support that they need and a platform to advocate for needed resources as well. It was also felt that working outside of one's skillsets is counterproductive to progress and understanding areas of expertise will contribute more to the team's success.

\section{Provide Adequate Resources}

Some deans felt that increasing leaders' focus on funding for academic offerings and focusing on providing and increasing resources were important to the university community. Availability of resources is important to the longevity of initiatives, programs and departments and participants highlighted the need to create shared resources and a space for faculty to collaboratively conduct their research. Having to prioritize resources can be a challenge, but one participant suggested that lower administrators be encouraged to ask only for what is needed to reduce time spent evaluating requests.

Another participant spotlighted on a resource that his institution created, an innovation center, which he maintained. As the dean and manager of the resource, he viewed himself as an enabler and supporter that brought faculty together with shared interest to utilize that space.

\section{Collaborate with External Educational Institutions}

One dean highlighted the commitment her university president made to provide resources to engage with local institutions that were in a five-mile radius. The goal of the partnership was to allow students to attain dual degrees. Her university also had a pipeline agreement with another larger, predominantly White university. In addition to seeking partnerships with other institutions of higher education, her university also had developed relationships with elementary and high schools. University students were trained on campus and then deliver the content via tutoring of younger K-12 students.

Another participant, who had a slightly different perspective, took a reflective look at the education system and emphasized the need for teacher education. While he did not directly state the need for universities to collaborate with the K-12 educational system, he felt that increasing teacher education in the United States was necessary for it to maintain its lead in the world.

\section{Practices that Strengthen Student STEM Communities at HBCUs}

\section{Human Resource Themes}

The ability to recruit and retain students is of the utmost priority to many institutions of higher education. As such, it was no surprise that investing in students was a theme that emerged. Participating deans placed a heavy emphasis on the importance of supporting and providing programs and opportunities for students. The following themes demonstrate how administrative members of successful HBCUs support their student community.

\section{Provide Authentic Experiences}

Deans felt that it was imperative to allow students to have authentic experiences while attending the university. Authentic experiences include allowing students to have their own unique research projects that are independent of faculty research. Often, in STEM, there are big projects and students may be responsible for certain components. However, students should generate their own independent research ideas.

One dean talked about engaging students in outreach and K-12 pipeline activities. His institution offered summer and Saturday sciences experiences and students who participated in science activities on Saturdays also tutored younger students in elementary and high schools. Providing outreach activities gave students opportunities to participate in co-curricular activities.

Another male dean felt that opportunities to participate in service-learning projects and research presentations should be available to students. When students conduct presentations at internal and external venues it allowed them to articulate the sciences better, communicate and network with professors at other schools and ultimately become more confident in their STEM abilities.

According to another male dean, African American students should not be taught in totally African American environments. He stated that his institution was diverse and actively promoted the concept of diversity. In his view, diversity was extremely important and claimed it was a fact that students taught in all-black environments would not survive.

Other authentic experiences stated by deans include helping students find confidence in their STEM abilities and providing them with experiences that extend the boundaries of the classroom. While these experiences may be categorized as learning, they may not be in traditional classroom spaces. 


\section{Create a Family-Like Environment}

One dean referenced the African proverb, it takes $a$ village to raise a child. In his perspective, everyone should work together to grow the students and send them on to great careers. Members of the university community should not only view each other as a family but also work together and trust one another. Another participant mentioned that the slogan at the institution referred to the university community as a family that grows scientists, or students. The slogan has been adopted to the point where shirts were produced with the saying on it.

\section{Express High Expectations}

One dean credited having high expectations of students to the students' heightened success at HBCUs. In addition, students should also be encouraged to know that it is their responsibility to learn. According to one dean, expectations of African Americans have been lowered based on their portrayal in the media. Without high expectations, African Americans and other minorities can get lost in the shuffle at universities. Another dean also mentioned that STEM expectations of students were high at her university as well. She expects students to aggressively pursue summer internships and research opportunities.

\section{Address Cultural Needs}

Some deans highlighted the need to improve students' cultural readiness and expose them to culturally responsible research. One participant expressed that students should be taught how to be "responsible with their science and what they allow their science to do". These students can then model for other students how it's done successfully, which results in improving STEM workforce diversity.

\section{Structural Theme}

\section{Expand Program Offerings and Opportunities}

Some deans expressed that increasing STEM opportunities was important for student growth and broadening participation. Some practices that were mentioned included creating summer programs and enrichment opportunities. One dean highlighted the institution's tutoring center that supports students, as well as an office dedicated to undergraduate research. One of the outcomes of that office is an undergraduate research journal that highlighted students who excelled in undergraduate research. In addition to those opportunities, the university also offered several on-campus leadership programs.

One male dean expressed a desire to have all students in the sciences complete at least one internship experience before leaving the institution. At the time of the interview, the participant was working on building relationships with other entities to ensure that students were able to intern at those entities. The goal was to build the program to start before students entered a program, at the recruitment phase, to culminate in an internship placement.

\section{Symbolic/Human Resource Theme}

One theme emerged that aligned with both the symbolic and human resource frames. The theme was a blend of investing in human potential and representing the mission or symbolism of the institution.

\section{Create a Sense of Community}

One participant mentioned the importance of creating a student sense of community, while another stated that she tries to understand the strategies that work best for underrepresented students. One of the female participants stated that HBCUs are relatively homogenous environments and, as a result, administration and faculty have a lot of experience with African American students in ways that build community.

\section{Practices that Strengthen STEM Faculty and Programs at HBCUs}

Participants expressed their perspectives on the importance of creating and implementing programs and initiatives that meet university and STEM needs. Analysis of the themes showed that these views aligned with structural and symbolic frames.

\section{Structural Themes}

\section{Encourage Faculty to Increase Research Aptitude}

A female dean focused heavily on research and acknowledged its importance when she mentioned that she ensures that the institution's infrastructure is able to support the resources needed for faculty to conduct research. She understood the necessity of providing the space and time for faculty to accomplish their work. This dean had an innovation center and the purpose of the center was to take faculty through a lean startup curriculum. It also taught faculty how to ask questions of the society around them to ensure that their research will have a lasting impact in their area of focus.

Another female dean touched on the need to have infrastructure in place to support the research needs of the faculty. One of the female participants mentioned a model that was developed for faculty to understand the benefits of working with students and how to manage that partnership in a way that did not impede the faculty's scholarship.

\section{Increase Inclusivity of STEM Projects to Other STEM and Non-STEM Departments/Programs}

A male dean mentioned that he tried to foster collaboration among departments so that each side knew 
what the other was doing. When collaborative proposals reached his desk, he would suggest that someone from a non-STEM department be included in the proposal to increase inter-disciplinary collaborations. His view of broadening participation was including every group that could participate in the STEM enterprise, even if it meant having to develop strategies or pedagogies best suited for the group or project.

\section{Provide Faculty with Strategies that Show How to Engage Students in Research}

A female dean stated that it was important for faculty to understand how to engage students in research in a way that "research stays rigorous and that the mentoring of the students is not taxing or does not take away from what [faculty members] were trying to do". Her goal was to create a model of engagement for other institutions to follow. Another female participant encouraged faculty to think about their research in different and creative ways, such as a commercial product.

\section{Create a Blend of Teaching Focused and Research Active Faculty}

One female dean, who was employed at a teaching institution, stressed that there was a need for faculty to find a balance between teaching and having time to do research. Although her HBCU was a teaching institution, she expressed that it was also research driven. According to this participant, institutions across the country have evolved in their expectations of research and scholarship.

\section{Expand and Improve STEM Programs}

One female dean listed getting the institution's distance learning prospectus approved by regional accreditation as one of her proudest achievements. She highlighted the work she did to assist with creating a new health sciences degree program.

\section{Characteristics of STEM Leaders at HBCUS}

\section{Symbolic Themes}

\section{Appreciate diversity}

Managing and appreciating diversity was the most frequently occurring symbolic theme that emerged from the analysis. One male dean stated that diversity was extremely important, while another expressed that he enjoyed working at his university because diversity was respected, appreciated and valued. A third participant was proud of his HBCU for contributing to nationwide diversity in STEM and a fourth male participant mentioned that young people should be educated in a diverse environment to prepare to survive in a diverse world.
A male participant stated that the number one skill he hoped that leaders learn from attending and leadership development training was the ability to manage a diverse faculty. The only female participant to mention diversity expressed the need to encourage faculty to think about how their research communicated the way diversity can be achieved in the STEM pipeline.

\section{Love the University Mission}

One female dean mentioned that she was drawn to her university because she loved its mission. She appreciated that STEM curriculum was at the heart of the mission.

Another female dean mentioned that she felt connected to the university when she arrived and could see students and faculty reflected in the institution's mission. According to the same participant, one strength of the university was the fact that approximately $85 \%$ of the institution's faculty were mission driven. She expressed that the faculty at the institution worked, "pay or no pay", to ensure that students and the campus were successful.

\section{Love Teaching}

A female dean attributed her success at her university to her intrinsic love for teaching that aligned with the institution's identity as a teaching institution. She appreciated the fact that there were opportunities to conduct research, but the primary focus was teaching.

\section{Be Trustworthy}

A male participant expressed that there can be the most competent person but, if he or she is not ethical, it will be difficult to trust that them to accomplish goals and tasks. Leaders should be trusted by faculty and be trusted to manage finances. Whomever was placed in a leadership position should have the best interest of the institution. Should the trust of those who follow be lost, a leader will not be unable to accomplish much. The leader also emphasized that institutions need honest, trustworthy leaders who are competent, as the two qualities go hand-in-hand.

\section{Have a Personal Faith}

A male participant felt that his faith, as a Christian, taught him to have patience, love and the ability to accommodate different types of persons he worked with while in a leadership position. He expressed that this was especially important working in a large organization.

\section{Being Passionate about STEM}

A male participant highlighted the fact that his university has faculty members who are very passionate about science. Their passion enables them to effectively implement certain practices aimed at student efficiency in STEM. 


\section{Challenges that Impact Leadership and Broadening Participation at HBCUS}

\section{Political Themes}

The themes that emerged that align with the political frame highlight challenges that the deans faced at their HBCUs that deal with resources and relationships with external institutions.

\section{Limited Resources}

Lack of resources was the challenge most mentioned by participants. One participant stated that infrastructure needs were a major overarching challenge. Another participant listed prioritizing departmental resource needs as a challenge. She felt that she often had to conduct investigations to truly get a clear representation of the needs of the faculty and department.

Another participant expressed frustration at having to attend meetings where he was the only HBCU chair in attendance. While others were talking about funding which were upwards of half a million dollars, he was hesitant to talk about his much lower budget.

\section{Feeling used by other Institutions Because of HBCU Status}

One of the female participants listed interacting with other institutions as challenge. She mentioned that there are times when non-HBCU entities want to engage with her HBCU to achieve needed numbers or for other reasons. As a result, she must make sure that her institution is not taken advantage of in the process. As a person who sat on several proposal review panels, she listed the promise of collaborating with an $\mathrm{HBCU}$ as a perpetual issue. Often, when she reviewed proposals that mentioned collaborating with an HBCU, there was limited evidence of having tried to contact the institution.

\section{Resistance from Older Faculty}

One of the problems one male dean faced was with older faculty who viewed newer faculty as "young whippersnappers" who received too much money. Although newer faculty may be paid market value, it did not deter the tension it created with older faculty.

\section{Structural Theme}

\section{Transitioning from a Teaching to a Research Institute}

One male dean mentioned older faculty also showed resistance to transitioning from teaching only to including research responsibilities, such as securing funding and publishing.

\section{Human Resource/Political Theme}

\section{Combating Age and Gender Limitations}

Another challenge faced by a female dean involved issues related to gender and age. She once had a faculty member who confided in her that the department head repeatedly asked her [the faculty] to perform secretarial work after the secretary quit. Another experience this dean shared was the difficulty her dean had to put her in a formal leadership position. It was not until she was ready accept a position at another institute that the participant was offered a permanent leadership position. According to the participant, there was an expectation, from her engineering perspective, that a leader needed to be in their 60 s before they could be in a leadership position.

\section{Discussion}

This study used narrative inquiry to explore and uncover the perspectives and experiences of eight deans. Of the 29 extracted themes, eight $(28 \%)$ were human resource, seven $(24 \%)$ were structural, six $(21 \%)$ were political, six $(21 \%)$ were symbolic, one $(3 \%)$ was blended human resource/symbolic and one (3\%) was blended human resource/political.

Five major themes emerged: (a) Practices of effective leaders; (b) practices that strengthen student STEM communities; (c) initiatives that strengthen STEM faculty and programs; (d) characteristics of STEM leaders; and (e) challenges that impact leadership and broadening participation. Each of the five themes had subthemes that were coded based on the four academic frames.

Most themes aligned with the human resource frame and the practice that appeared to have the highest importance was participate in and provide and leadership development opportunities. A major emphasis was placed on the benefits of participating in and need to provide and leadership development opportunities for themselves and their academic leaders. Several of the deans accredited their success to the trainings and support they received throughout their careers. Eva et al. (2019) view of servant leadership, which stated that servant leaders empower followers to grow into what they can become, strongly supported and aligned with this theme.

Providing authentic experiences and opportunities for the student community was also another practice that ranked highly among the themes. Service-learning projects, outreach activities and expanding the boundaries of the classroom were some of the various ways that participants felt were necessary to create lifelong STEM learners and a unique experience. Creating a family-like, diverse campus was also important, given the unique nature and environment of HBCUs.

The deans shared their perspectives on their institutions and on themselves as well. Six characteristics 
of the interviewed participants emerged in the data and aligned with the symbolic frame: (a) Appreciating diversity; (b) loving the university mission; (c) loving teaching; (d) being trustworthy; (e) having a personal faith; and (f) being passionate about STEM. Interestingly, the characteristics did not align with any other academic frame. Further research into leadership characteristics of STEM HBCU leaders may yield an explanation or support this early finding that STEM leaders' characteristics are symbolic in nature.

Having an appreciation for diversity was the characteristic of the STEM leaders with the greatest recurrence. Appreciating diversity is supported by (Mehta et al., 2020), who stated that responsible leaders should be able to find value in people from various backgrounds and engage them for a common good. The ability to navigate the differences of individual personalities and work ethics also aligned with the role of a responsible leader.

When evaluating the challenges that impacted STEM leadership and broaden participation, it was interesting to discover that this theme aligned with three out of four academic frames: Political, structural and human resource/political. Challenges ranged from lack of resources to combating issues related to age and gender to transitioning from a teaching to research institution. Given recent research, which highlighted limited funding as a hurdle for HBCUs (Johnson, 2013), it was unsurprising that limited resources were the biggest challenge. This research team speculated that the challenges didn't align with the symbolic frame due to HBCUs legacy of providing culturally relevant education to its students (Esmieu and Martinez, 2014).

\section{Conclusion}

This research study suggested an academic framework through which leadership styles at educational institutions can be viewed. It also uncovered perspectives, practices and behaviors of current STEM leaders that appear to impact broadening participation. There were several promising practices employed by these leaders that can be implemented at other universities and colleges to improve their STEM infrastructure and support the university community.

HBCUs are valuable educational institutions that significantly contribute to the education of many Americans. When an HBCU combines effective leadership styles and practices with a strong focus on STEM building and infrastructure, there can be a resulting increase in broadening participation in STEM. Future studies that analyze the behaviors, perceptions and institutional outcomes are needed to build on this study.

\section{Acknowledgement}

This work was supported by the National Science Foundation through the Center for the Advancement of STEM Leadership (CASL) under NSF Grant No. 1818424, 1818425, 1818447 and 1818459. Any opinions, findings and conclusions or recommendations expressed in this report are those of the authors and do not necessarily reflect the views of the National Science Foundation.

\section{Funding Information}

This research was funded by an NSF grant awarded to the Center for the Advancement of STEM Leadership.

\section{Author's Contributions}

Nisha Naomi Clavier: Made considerable contributions to the conception, design and writing of the article. She also reviewed the paper for significant intellectual content, analyzed and interpreted the data and gave final approval of the article.

Camille A. McKayle: Contributed to conception and design of the article, organized data collection, reviewed the paper critically for significant intellectual content and gave final approval of the articles and its revisions, to be submitted.

Kimarie Engerman: Made considerable contributions to the conception and design, acquisition of data, analysis and interpretation of data, drafting of the article and reviewing it critically for significant intellectual content and gave final approval of the article and its revisions, to be submitted.

Mohomodou Boncana: Made considerable contributions to conception and design, analysis and interpretation of data, drafting of the article and reviewing it critically for significant intellectual content. He suggested revisions but passed away before he could give his final approval of the paper.

\section{Ethics}

The authors confirm that the content of the article does not violate the confidentiality or reputations of any participants or institutions, nor will any ethical issues arise after the publication of this manuscript.

\section{References}

Azanza, G., Moriano, J. A., \& Molero, F. (2013). Authentic leadership and organizational culture as drivers of employees' job satisfaction. Revista de Psicología del Trabajo y de las Organizaciones, 29(2), 45-50. https://doi.org/10.5093/tr2013a7 
BlackPast. (2020, October 1). Cheyney University of Pennsylvania. https://www.blackpast.org/africanamerican-history/cheyney-university-pennsylvania$1837 /$

Bolman, L. G., \& Gallos, J. V. (2011). Leading from the middle. Reframing academic leadership [electronic resource](, 143-162.

Bolman, L. G., \& Deal, T. E. (1991). Reframing organizations: Artistry, choice and leadership. https://psycnet.apa.org/record/1991-97421-000

Bukit, P., Yamali, F. R., \& Ananda, R. (2019). Pengaruh Gaya Kepemimpinan Terhadap Kinerja Pegawai dengan Motivasi dan Disiplin Kerja Sebagai Variabel Intervening Pada Dinas Pekerjaan Umum dan Perumahan Rakyat Provinsi Jambi. J-MAS (Jurnal Manajemen dan Sains), 4(2), 413-422. https://doi.org/10.33087/jmas.v4i2.127

Cismas, S. C., Dona, I., \& Andreiasu, G. I. (2016). Responsible leadership. Procedia-Social and Behavioral Sciences, 221(5), 111-118. https://doi.org/10.1016/j.sbspro.2016.05.096

Diana-Nicoleta, G., Adriana-Iuliana, F. C., \& MonicaIoana, T. (2019). The Importance Of Leadership Training Skills. Annals-Economy Series, 6, 313-318. https://www.utgjiu.ro/revista/ec/pdf/201906/45_Georgescu.pdf

Dugan, J. P., \& Komives, S. R. (2010). Influences on college students' capacities for socially responsible leadership. Journal of College Student Development, 51(5), 525-549. https://doi.org/10.1353/csd.2010.0009

Esmieu, P., \& Martinez, A. (2014). Expanding the HBCU legacy: Enrolling and supporting the rising Latino population. In Opportunities and Challenges at Historically Black Colleges and Universities (pp. 107-127). Palgrave Macmillan, New York. https://doi.org/10.1057/9781137480415_8

Eva, N., Robin, M., Sendjaya, S., van Dierendonck, D., \& Liden, R. C. (2019). Servant leadership: A systematic review and call for future research. The Leadership Quarterly, 30(1), 111-132. https://doi.org/10.1016/j.leaqua.2018.07.004

Flowers, L. O., White, E. N., Raynor, J. E., \& Bhattacharya, S. (2012). African American students' participation in online distance education in STEM disciplines: Implications for HBCUs. SAGE Open, 2(2), 1-5. https://doi.org/10.1177/21582440124435 44

Gonzalez, H. B., \& Kuenzi, J. J. (2012, August). Science, technology, engineering and mathematics (STEM) education: A primer. Washington, DC: Congressional Research Service, Library of Congress. http://steamwise.io/docs/congressionalresearch-service-R42642.pdf
Han, Z., Wang, Q., \& Yan, X. (2019). How responsible leadership motivates employees to engage in organizational citizenship behavior for the environment: A double-mediation model. Sustainability, $11(3), \quad 605$. https://doi.org/10.3390/su11030605

Harper, C. (2018). HBCUs, Black women and STEM success. Higher education today. https://www.higheredtoday.org/2018/05/14/hbcusblack-women-stem-success/

Heimann, A. L., Ingold, P. V., \& Kleinmann, M. (2020). Tell us about your leadership style: A structured interview approach for assessing leadership behavior constructs. The Leadership Quarterly, 31(4), 101364. https://doi.org/10.1016/j.leaqua.2019.101364

Hines, R. (2014). Rethinking and reframing leadership of historically Black colleges and universities: A distributed perspective. Creative Education, 2014. https://www.scirp.org/html/3-6302192_47798.htm

Hurduzeu, R. E. (2015). The impact of leadership on organizational performance. SEA-Practical Application of Science, 3(07), 289-293. https://www.ceeol.com/search/article-detail?id=741494

Ikinci, S. S. (2014). Organizational change: Importance of leadership style and training. Management and Organizational Studies, 1(2), 122-128. https://doi.org/10.5430/mos.v1n2p122

Insights Into Inclusive STEM High Schools. (2020, October 1). What is an inclusive STEM high school? https://inclusivesteminsights.sri.com

Johnson, M. N. (2013). Financial and related issues among historically black colleges and universities. Journal of Intercollegiate Sport, 6(1), 65-75. https://doi.org/10.1123/jis.6.1.65

Kaptein, M. (2019). The moral entrepreneur: A new component of ethical leadership. Journal of Business Ethics, 156(4), 1135-1150. https://doi.org/10.1007/s10551-017-3641-0

Khan, M. A., Ismail, F. B., Hussain, A., \& Alghazali, B. (2020). The interplay of leadership styles, innovative work behavior, organizational culture and organizational citizenship behavior. SAGE Open, $\quad$ 10(1), 2158244019898264. https://doi.org/10.1177/2158244019898264

Lancaster, C., \& Xu, Y. J. (2017). Challenges and supports for African American STEM student persistence: A case study at a racially diverse four-year institution. The Journal of Negro Education, 86(2), 176-189. https://doi.org/10.7709/jnegroeducation.86.2.0176

Lynch, S. J., Spillane, N., Burton, E. P., Behrend, T., Ross, K., House, A., \& Han, E. M. (2013). Manor New Tech High School: A case study of an inclusive STEMfocused high school in Manor, Texas. https://ospri.research.gwu.edu/sites/g/files/zaxdzs2456/ f/downloads/OSPrI_Report_2013-01.pdf 
Means, B., Wang, H., Wei, X., Iwatani, E., \& Peters, V. (2018). Broadening participation in STEM college majors: Effects of attending a STEM-focused high school. AERA Open, 4(4), 2332858418806305. https://doi.org/10.1177/2332858418806305

Mehta, M., Sarvaiya, H., \& Chandani, A. (2020). Community engagement through responsible leadership in managing pandemic: insight from India using netnography. International Journal of Sociology and Social Policy. https://doi.org/10.1108/IJSSP-06-2020-0214

Miriti, M. N. (2019). Nature in the eye of the beholder: A case study for cultural humility as a strategy to broaden participation in STEM. Education Sciences, 9(4), 291. https://doi.org/10.3390/educsci9040291

National Center for Education Statistics. (2020, October 1). Historically black colleges and universities. https://nces.ed.gov/fastfacts/display. $\cdot$ asp?id=667

Owens, E. W., Shelton, A. J., Bloom, C. M., \& Cavil, J. K. (2012). The significance of HBCUs to the production of STEM graduates: Answering the call. Educational Foundations, 26, 33-47. https://eric.ed.gov/?id=EJ1000229

Pless, N. M., \& Maak, T. (2011). Responsible leadership: Pathways to the future. In Responsible leadership (pp. 3-13). Springer, Dordrecht. https://doi.org/10.1007/978-94-007-3995-6_2

Saleem, A., Aslam, S., Yin, H. B., \& Rao, C. (2020). Principal Leadership Styles and Teacher Job Performance: Viewpoint of Middle Management. Sustainability, 12(8), 3390. https://doi.org/10.3390/su12083390

Saxena, A., Desanghere, L., Stobart, K., \& Walker, K. (2017). Goleman's Leadership styles at different hierarchical levels in medical education. BMC medical education, 17(1), 169. https://doi.org/10.1186/s12909-017-0995-z
Shah, B. (2018). Effective leadership in organization. European Journal of Business Management and Research, 3(3), 1-5. https://doi.org/10.24018/ejbmr.2018.3.3.13

Thapa, K. B. (2016). Present and Importance levels leadership competencies of principals in Nepalese Schools. Journal of Advanced Academic Research, 3(1), 111-122. https://doi.org/10.3126/jaar.v3i1.16621

TMCF. (2020) History of HBCUs. Available online: https://www.tmcf.org/history-of-hbcus/

U.S. Department of Education. (2020a, October 1). Historically black colleges and universities and higher education desegregation. https://www2.ed.gov/about/offices/list/ocr/docs/h q9511.html

U.S. Department of Education. (2020b, October 1). Science, technology, engineering and math, including computer science. https://www.ed.gov/stem

United Negro College Fund. (2020, October 1). The impact of HBCUs on diversity in STEM fields. https://uncf.org/the-latest/the-impact-of-hbcus-ondiversity-in-stem-fields

Watson, J. E. (2013). Education experts concerned about the future of HBCUs as leadership frequently changes. Diverse Issues in Higher Education, 30(18), https://search.proquest.com/openview/40a09a1bb1d 72bca3664dda3519ad94a/1.pdf?pqorigsite $=$ gscholar $\&$ cbl $=27805$ 